\title{
Incidence and Severity of Intra-Ventricular Haemorrhage (IVH) in Preterm Infants, Northeast of Iran
}

\author{
Fouladinejad $\mathbf{M}^{1}$, Khorsand zak $\mathrm{H}^{2}$, Nematollahi $\mathbf{N}^{3}$, Alaee $\mathrm{E}^{4}$
}

${ }^{1}$ Dr. Mahnaz Fouladinejad, Neonatologist, Assistant Professor, Neonatal and Children's Health Research Center, Golestan University of Medical Sciences, Gorgan, Iran. ${ }^{2} \mathrm{Dr}$. Hadi Khorsand zak, Department of Paediatrics, North Khorasan University of Medical Sciences, Bojnurd, Iran. ${ }^{3} \mathrm{Dr}$. Nematollah Nematollahi, Radiologist, Assistant Professor, Golestan University of Medical Sciences, Gorgan, Iran. ${ }^{4}$ Dr. Ehsan Alaee, Neonatologist, Assistant Professor, Neonatal and Children's Health Research Center, Golestan University of Medical Sciences, Gorgan, Iran.

\section{Address for correspondence:}

Dr. Mahnaz Fouladinejad

Assistant Professor and Neonatologist,

Neonatal and Children's Health Research Centre,

Golestan University of Medical Sciences,

Gorgan, Iran.

Tel No: +989111716302

E-mail: m_fouladinejad@yahoo.com

Acknowledgements: We would like to thank all people who participated in this study.

Funding: Nil

Conflict of Interest: None

Permission from IRB: Yes

Ethical dilemmas faced during study: None

\section{How to cite}

Fouladinejad M, Khorsand zak $\mathrm{H}$, Nematollahi $\mathrm{N}$, Alaee E. Incidence and Severity of IntraVentricular Haemorrhage (IVH) in Preterm Infants, Northeast of Iran. J Nepal Paediatr Soc 2016;36(1):38-41.

doi: http://dx.doi.org/10.3126/jnps.v36i1.14457

This work is licensed under a Creative Commons Attribution 3.0 License.

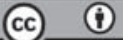

\begin{abstract}
Introduction: The incidence rate of Intra-Ventricular Haemorrhage (IVH) varies from $20 \%$ to $25 \%$ among preterm infants with a very low birth weight. IVH could compose critical disabilities which are directly associated to its grade. The aim of this study was to evaluate the incidence and severity of IVH in preterm infants referred to the academic Hospital of Gorgan, Northeast of Iran. Materials and Methods: In this crosssectional study, we examined all preterm infants who had been referred to the academic Hospital of Gorgan, Northeast of Iran between Augusts 2014 and February 2015. Seventy one preterm infants ( $\leq 34$ weeks of gestation, $\leq 1500 \mathrm{~g}$ birth weight) have been included. Cranial ultrasound was done within 3-5 days of birth for all subjects and subsequent ultrasounds were performed based on their birth weight by portable ultrasound device. Results: The overall incidence of IVH was $64.8 \%$ in the present study. There was a significant relationship between IVH incidence and the gestational age $(p=0.010)$. Also the lower birth weight was associated to the higher rate of IVH complications reported in sequential ultrasounds $(p<0.05)$. Conclusion: Gestational age and birth weight seem to have key roles in the occurrence and severity of IVH, respectively.
\end{abstract}

Key words: Intra-ventricular haemorrhage; ultrasound; preterm infants; low birth weight

\section{Introduction}

$\mathrm{T}$ he incidence rate of Intra Ventricular Haemorrhage (IVH) has been reported $20 \%$ to $25 \%$ among preterm infants with an extremely low birth weight and $45 \%$ in those weighing $500-750 \mathrm{gm}^{1}$, and remains as a major complication of preterm labour resulting in certain critical disabilities ${ }^{2,3}$. Those infants with a gestational age less than 28 weeks are more susceptible to IVH, and those who survive will show signals of neuro-developmental failures and long-term disabilities ${ }^{4,5}$.

Periventricular germinal matrix is the onset location of the IVH where the neuronal precursor cells and glial are accumulated ${ }^{6}$. In preterm infants, this region is vulnerable to haemorrhage mainly in the first 48 hours of life. If the haemorrhage in the germinal matrix is 
outstanding, the ependyma may break and thus, blood will fill the cerebral ventricle. IVH is considered to be result of a developing germinal matrix haemorrhage ${ }^{7}$. Cranial ultrasound is performed to reach the most accurate diagnosis in these infants and also as a screening process in asymptomatic ones ${ }^{1}$.

The survival rate of preterm infants is decreased mainly due to increased risk of neurological disorders. The mortality rate of neonates with severe IVH is noticeably higher than those without IVH ${ }^{8}$. The IVH presentations are directly associated with the IVH grades; moderateto-severe IVH (grade 3-4) exposes infants to a high risk of cerebral palsy, post-haemorrhagic hydrocephalus, mental retardation and peri-ventricular leukomalacia; while infants with mild IVH (grade 1-2) can be at the risk of certain developmental disabilities ${ }^{9,10,11}$.

There are some associations between the occurrence of IVH and series of prenatal and postnatal events $^{12}$.

The aim of this study was to evaluate the incidence and severity of Intra-Ventricular Haemorrhage (IVH) in preterm infants in Gorgan, Northeast of Iran.

\section{Material and Methods}

This was a cross-sectional study where we examined all preterm infants who had been referred to Sayyad Shirazi Hospital of Gorgan, during August 2012 to February 2013. Seventy one preterm infants ( $\leq 34$ weeks, $1500 \mathrm{gm}$ sbirth weight) have been included considering the following inclusion criteria:

1. Gestational age $\leq 34$ weeks and birth weight $\leq$ $1500 \mathrm{gm}$,

2. All born at the same hospital and

3. Being available for follow-up until the end of the $40^{\text {th }}$ week post conception age.

Mother and infant underlying data were recorded in a checklist including: mother age, medical history, drug history, infant $1^{\text {st }}$ and $5^{\text {th }}$ second APGAR, birth weight and gestational age. We performed cranial ultrasound using portable ultrasound device (Hyundai 2000) during the first week of birth (3-5 days after birth) in all infants and subsequent ultrasounds have been performed in accordance to their birth weight as followings ${ }^{13}$ :

a. Birth weight $\leq 1000 \mathrm{gm}$ : the first ultrasound was performed at day 3-5; the second one at day 10-14 and the third one was conducted on the 28th day after birth. The final ultrasound was done before the hospital discharge to diagnose the late onset lesions. b. Birth weight $1000 \mathrm{gm}$ - $1250 \mathrm{gm}$ : first ultrasound was performed at day 3 to 5 , the second on the 28th day and the third was performed before discharge to diagnose the late onset lesions.

c. Birth weight $1250 \mathrm{gm}$ - $1500 \mathrm{gm}$ : first ultrasound was performed at day 3 to 5 and the second before discharge.

d. If higher degrees of IVH had been reported, next ultrasound would have to be performed according to the protocol.

e. All dead infants underwent ultrasound examination of IVH.

We divided the severity of haemorrhage into four major categories based on the bleeding situation and intensity of ventricular dilatation in the ultrasound ${ }^{14}$.

Grade I: Haemorrhage was restricted to germinal of matrix or less than $10 \%$ of ventricle.

Grade II: Intra-ventricular haemorrhage filled $10 \%$ $50 \%$ of ventricle without ventricular dilatation.

Grade III: Over 50\% involvement of ventricle with acute ventricular dilatation

Grade IV: Ventricular involvement with or without dilatation accompanied by intra-parenchymal haemorrhage.

The last cranial ultrasound of the dead infants was conducted within 24 hours after the occurrence. To investigate late onset complications, ultrasound was followed up for 40 weeks of the modified gestational age.

Data Analysis was done by using the Chi-square test, logistic regression, and correlation tests were applied. The significance level was considered 0.05.

After approval of the Ethics Committee of Golestan University of Medical Sciences, we explained the importance of the project to the parents and informed consent was taken.

\section{Results}

The overall incidence of IVH was $64.8 \%$ in the present study. There was a significant relation between IVH incidence and the gestational age $(p=0.010)$ but the severity of IVH and the gestational age were not significantly related $(p=0.255)$.

Pearson Chi-Square clarified a significant association between the IVH grade and its complications and the low birth weight $(p=0.046)$. 
Table 1: Showing severity of IVH within days 3-7, 10-14, 28, discharge time, and 40th weeks of the modified gestational age and after death

\begin{tabular}{ccccccc}
\hline & \multicolumn{5}{c}{ Time of the Ultrasound examination(days) } \\
\cline { 2 - 7 } Grade of IVH & $\mathbf{3 - 7}$ & $\mathbf{1 0 - 1 4}$ & $\mathbf{2 8}$ & Discharge & $\begin{array}{c}\text { 40 weeks of modified } \\
\text { gestational age }\end{array}$ & After death \\
\hline No IVH & $31(45.6 \%)$ & $7(24.1 \%)$ & $12(35.3 \%)$ & $38(73.1 \%)$ & $53(94.64 \%)$ & - \\
\hline Grade 1 & $17(25 \%)$ & $11(37.9 \%)$ & $11(32.4 \%)$ & $9(17.3 \%)$ & $3(5.36 \%)$ & $1(7.1 \%)$ \\
\hline Grade 2 & $11(16.2 \%)$ & $3(10.3 \%)$ & $3(8.8 \%)$ & $2(3.8 \%)$ & - & $1(7.1 \%)$ \\
\hline Grade 3 & $4(5.9 \%)$ & $4(13.8 \%)$ & $7(20.6 \%)$ & $2(3.8 \%)$ & - & $2(14.3 \%)$ \\
\hline Grade 4 & $5(7.4 \%)$ & $4(13.8 \%)$ & $1(2.9 \%)$ & $1(1.9 \%)$ & - & $10(71.4 \%)$ \\
\hline Total & $\mathbf{6 8 ( 9 5 . 8 \% )}$ & $\mathbf{2 9 ( 4 0 . 8 \% )}$ & $\mathbf{3 4 ( 4 7 . 9 \% )}$ & $\mathbf{5 2 ( 7 3 . 2 \% )}$ & $\mathbf{5 6}(\mathbf{7 8 . 9 \% )}$ & $\mathbf{1 4 ( 1 9 . 7 \% )}$ \\
\hline
\end{tabular}

There were no complications of IVH in $60(88.2 \%)$ patients.

Within days 3-7 and day 28 after birth, and at the discharge ultrasound examination revealed a significant relation between the IVH grade and its complications $(p=0.05)$.

Fifteen $(21.13 \%)$ cases died before the end of the $40^{\text {th }}$ week of the gestational modified age. There was a significant relationship between the gestational age and death rate before 40 th weeks of the modified gestational age $(p<0.05)$.

Post-mortem ultrasound showed that $100 \%$ of the dead cases had abnormal cranial ultrasound.

\section{Discussion}

In the present study on 71 preterm infants in Northeast of Iran, we found a significant difference in the IVH incidence regards to the gestational age. Nevertheless, there was no association between the severity of IVH and the gestational age.

Mulindwa et al. studied the prevalence of intraventricular haemorrhage and the associated risk factors in preterm neonates and reported grade 1 (mild) IVH as the most frequent condition among preterm infants with a birth weight of $1.5 \mathrm{~kg}^{15}$.

Klebermass-Schrehof et al. surveyed the impact of low grade Intra-Ventricular Haemorrhage on long-term neuro-developmental outcomes in preterm infants and reported an increase of abnormal results with a rising grade of $\mathrm{IVH}^{16}$. This was consistent with our findings. Furthermore, they claimed that the gestational age influences the impact of intra-ventricular haemorrhage on the neuro-developmental outcome ${ }^{16}$ which was in accordance with our results.

Chen et al. studied the incidence of brain injuries in premature infants with gestational age $\leq 34$ weeks in ten urban hospitals in China. Through basically similar methods, they presumed PVL as the major complication of $\mathrm{IVH}^{17}$; which is also consistent with our results.

\section{Conclusion}

We found that the gestational age plays a key role in the incidence of IVH while there appeared to be no association between IVH severity and the gestational age.

\section{References}

1. Rios DR, Welty SE, Gunn JK, Beca J, Minard CG, Goldsworthy M, et al. Usefulness of routine head ultrasound scans before surgery for congenital heart disease. Pediatrics 2013;131(6):1765-70.

2. McCrea HJ, Ment LR. The diagnosis, management, and postnatal prevention of intraventricular hemorrhage in the preterm neonate. Clin Perinatol 2008;35(4):77792.

3. Whitelaw A, editor Intraventricular haemorrhage and posthaemorrhagic hydrocephalus: pathogenesis,

prevention and future interventions. Semin Neonatol 2001: Elsevier.

4. Ment LR, Vohr B, Allan W, Katz KH, Schneider KC, Westerveld $\mathrm{M}$, et al. Change in cognitive function over time in very low-birth-weight infants. J Am Med Assoc 2003;289(6):705-11.

5. Mercier CE, Dunn MS, Ferrelli KR, Howard DB, Soll RF, Group VONEIF-US. Neurodevelopmental outcome of extremely low birth weight infants from the Vermont Oxford Network: 1998-2003. Neonatology 2009;97(4):329-38. 
6. Towbin A. Cerebral intraventricular hemorrhage and subependymal matrix infarction in the fetus and premature newborn. Am J Pathol 1968;52(1):121.

7. Brouwer AJ, Groenendaal F, Benders MJ, de Vries LS. Early and late complications of germinal matrixintraventricular haemorrhage in the preterm infant: what is new? Neonatology 2014;106(4):296-303.

8. Stoll BJ, Hansen NI, Bell EF, Shankaran S, Laptook AR, Walsh MC, et al. Neonatal outcomes of extremely preterm infants from the NICHD Neonatal Research Network. Pediatrics 2010;126(3):443-56.

9. Chamilos C, Sgouros S. Intrauterine grade IV intraventricular hemorrhage in a full-term infant leading to hydrocephalus. Childs Nerv Syst 2013;29(5):861-5.

10. Ting ET, Golomb MR. Grade IV fetal intracranial hemorrhage with good cognitive function. Pediatr Neurol 2010;42(3):231-3.

11. Volpe JJ. Neurobiology of periventricular leukomalacia in the premature infant. Pediatr Res 2001;50(5):55362.

12. Vohr B, Ment L. Intraventricular hemorrhage in the preterm infant. Early Hum Dev 1996;44(1):1-16.

13. Mirmiran M, Barnes PD, Keller K, Constantinou JC,
Fleisher BE, Hintz SR, et al. Neonatal brain magnetic resonance imaging before discharge is better than serial cranial ultrasound in predicting cerebral palsy in very low birth weight preterm infants. Pediatrics 2004;114(4):992-8.

14. Hemphill JC, Bonovich DC, Besmertis L, Manley GT, Johnston SC. The ICH score a simple, reliable grading scale for intracerebral hemorrhage. Stroke 2001;32(4):891-7.

15. Mulindwa M, Sinyangwe S, Chomba E. The Prevalence of Intraventricular Haemorrhage and Associated Risk Factors in Preterm Neonates in the Neonatal Intensive Care Unit at the University Teaching Hospital, Lusaka, Zambia. Med J Zambia 2012;39(1).

16. Klebermass-Schrehof $\mathrm{K}$, Czaba C, Olischar $\mathrm{M}$, Fuiko R, Waldhoer T, Rona Z, et al. Impact of lowgrade intraventricular hemorrhage on long-term neurodevelopmental outcome in preterm infants. Childs Nerv Syst 2012;28(12):2085-92.

17. Chen H-J, Wei K-L, Zhou C-L, Yao Y-J, Yang Y-J, Fan $X-F$, et al. Incidence of brain injuries in premature infants with gestational age $\leq 34$ weeks in ten urban hospitals in China. World J Pediatr 2013;9(1):17-24. 